\title{
The Parkinson's disease and restless legs syndrome/Willis-Ekbom disorder link: evidences, biases and clinical relevance
}

\author{
A conexão doença de Parkinson: síndrome das pernas inquietas / doença de \\ Willis-Ekbom: evidências, vieses e relevância clínica
}

Renato Puppi Munhoz ${ }^{1,2}$, Maria C. L. Constantino ${ }^{3}$, Laura Silveira-Moriyama ${ }^{4,5}$

\begin{abstract}
Parkinson's disease (PD) and restless legs syndrome/Willis-Ekbom disorder (RLS/WED) are relatively common diseases in the realm of movement disorders. The fact that both may, as expected, co-occur and typically share a similar remarkable response to dopaminergic treatment raised the interest in exploration of additional shared features that throughout the years cruised fields as diverse as phenomenology, epidemiology, genetics, pathology, and clinical studies. In this review, we describe and critically examine the evidence and biases of a conceivable overlap of these two disorders, trying to shed light onto two main sources of confusion: (1) are PD and RLS/WED reciprocal risk factors? and (2) what are the main mimics of RLS/WED in PD?
\end{abstract}

Keywords: Parkinson disease; restless legs syndrome.

\section{RESUMO}

A doença de Parkinson (DP) e a síndrome das pernas inquietas/doença de Willis-Ekbom (SPI/DWE) são doenças relativamente comuns no campo dos distúrbios do movimento. $O$ fato de que ambas podem, como esperado, ocorrer de forma simultânea e usualmente apresentarem resposta favorável ao tratamento dopaminérgico levaram ao interesse em explorar características compartilhadas adicionais. Ao longo dos últimos anos, essa busca percorreu campos diversos como a fenomenologia, epidemiologia, genética, patologia e estudos clínicos. Nesta revisão, analisamos e discutimos criticamente as evidências e os vieses de sobreposição concebíveis dessas duas doenças, tentando esclarecer duas perguntas sem resposta precisa até o momento: (1) DP e SPI/DWE representam fatores de risco recíprocos? e (2) quais são os principais mimetizadores da SPI/DWE na DP?

Palavras-chave: Doença de Parkinson; sindrome das pernas inquietas.

Parkinson's disease (PD) is the second most common neurodegenerative disorder, occurring in $1-2 \%$ of the population over the age of 65 years old. It is clinically characterized by an asymmetric combination of movement disorders, namely bradykinesia plus rigidity, tremor or postural instability, in addition to a variety of nonmotor signs and symptoms that range from hyposmia, to sleep disturbances and cognitive deficits ${ }^{1}$. This myriad of manifestations reflects the fact that PD is pathologically related to multiple functional structural and biochemical abnormalities, the most characteristic being the degeneration of dopaminergic neurons in the substantia nigra (SN) pars compacta, a pathological facet that endorsed the introduction of dopaminergic replacement as a highly effective therapeutic intervention in $\mathrm{PD}^{2}$.

Response to dopaminergic agents is also a feature of restless legs syndrome/Willis-Ekbom disorder (RLS/WED), which is recognized and defined clinically by the urge to move the lower extremities, usually due to uncomfortable sensations in the legs (occasionally also in other body parts). The sensations tend to occur or worsen towards the end of the day and during periods of rest, while the individual is in a lying or, less frequently, sitting position. These symptoms improve completely

\footnotetext{
${ }^{1}$ University of Toronto, Toronto Western Hospital, Movement Disorders Centre, Toronto ON, Canada;

${ }^{2}$ Krembil Research Institute, Toronto, Ontario, Canada;

${ }^{3}$ Universidade Federal de Pernambuco, Recife PB, Brasil;

«Universidade Nove de Julho, São Paulo SP, Brasil;

5Universidade Estadual de Campinas, Departamento de Neurologia, Campinas SP, Brasil.

Renato Puppi Munhoz (iD) https://orcid.org/0000-0002-4783-4067

Correspondence: Renato P. Munhoz; Toronto Western Hospital - 399 Bathurst Street - Toronto, ON - Canada - M5T 2S8; E-mail: renato.munhoz@uhn.ca

Conflict of interest: There is no conflict of interest to declare.

Received 14 May 2018; Received in final form 21 August 2018; Accepted 05 September 2018.
} 
or partially by movement, such as walking or stretching. Mimics of RLS/WED, such as akathisia, myalgias, venous stasis, edema, arthritis, among others, need to be ruled out ${ }^{3}$.

The response to dopaminergic agents such as levodopa or non-ergot dopamine agonists (i.e., pramipexole and ropinirole) can be dramatic but doses and regimen (daily dose at the end of the day vs. "as needed") vary according to individual needs. Over time, however, these interventions are complicated by a striking tendency for the quick development of tolerance to therapy, losing the benefits of medication within weeks or months. In addition, patients on continuous treatment with these drugs describe a phenomenon known as augmentation, defined by an increase in symptoms severity compared to their baseline, with earlier onset of symptoms at night or during the day, shorter latency to onset of symptoms upon lying still/sitting, and symptoms spreading to other body parts including genitals and upper extremities ${ }^{4}$. Another link between these two conditions is that both can be caused by dopamine blocking agents, such as neuroleptics, but while the link between parkinsonism and neuroleptics is very strong and dose-dependent, there is controversy as to whether neuroleptics really induce RLS/WED ${ }^{5,6}$.

The crossroad of these two disorders lies not only on the above-mentioned response to dopaminergic replacement strategies, but also on the view that both could happen simultaneously at a rate higher than chance, both share some common aspects of pathophysiology, and both present with similar phenomenology. The correlation between PD and primary RLS/WED has continued to be debated in recent years, fueled by developing interests in exploring the idea that the two diseases may share the same etiopathogenesis in the central dopaminergic system. The issue is still under debate and there are arguments for and against it ${ }^{7}$. From a broad and superficial point of view however, differences between these two diseases are clear. Parkinson's disease is a chronic degenerative disease with slow progression, while it is unknown whether RLS/ WED is a progressive condition or a disease that can broaden its phenotypic spectrum over time ${ }^{1,3}$. The prevalence of RLS/ WED is estimated at $5-15 \%$ of the general population ${ }^{3}$ while PD occurs in about $1-2 \%$ of individuals over 65 years of age ${ }^{1}$. Also, as outlined in the previous paragraph, the phenomenology of both conditions is quite distinct. In this review, we attempted to analyze the congruous and divergent aspects of these intricate disorders, in light of epidemiological, pathophysiological, functional, genetic and clinical data, highlighting the potential biases and confounding factors in their association. From a clinical point of view, our aim was to shed light on two main unanswered questions: (1) are PD patients more susceptible to developing true RLS/WED or vice versa? and (2) what features of PD may manifest as RLS/WED-like symptoms and be a source of diagnostic confusion?

\section{PATHOLOGICAL AND FUNCTIONAL IMAGING DATA}

A comparative summary of the similarities and differences between PD and RLS/WED is shown in Table 1.

Although there is general agreement on the fact that treatment with dopaminergic drugs induces a dramatic symptomatic improvement in RLS/WED as it does in PD, there is little, if any, solid evidence from pathological, and both standard and functional imaging studies, indicating a pathophysiological relationship between the two disorders. This lack of evidence has been demonstrated using diverse techniques such as, for instance, transcranial ultrasonography findings and postmortem studies of patients with RLS/WED, which did not demonstrate any of the typical pathological characteristics of $\mathrm{PD}$, such as accumulation of $\alpha$-synuclein in Lewy bodies ${ }^{8,9}$.

From a pathological standpoint, the topographic substrate of the physiological disturbance in RLS/WED has not been well defined. Again, despite the typical good response seen after dopamine replacement therapy, suggesting a role of this neurotransmitter as a bedrock for the genesis of RLS/

Table 1. Comparative summary of Parkinson's disease and restless legs syndrome/Willis-Ekbom disorder.

\begin{tabular}{|c|c|c|c|}
\hline Variable & Parkinson's disease & RLS/WED & Comparison \\
\hline Response to dopaminergic drugs & Positive & Positive & Similar \\
\hline $\begin{array}{l}\text { Long-term response to } \\
\text { dopaminergic drugs }\end{array}$ & $\begin{array}{c}\text { Limited by dyskinesias and nonmotor } \\
\text { symptoms }\end{array}$ & $\begin{array}{l}\text { Limited by tolerance and } \\
\text { augmentation }\end{array}$ & Somewhat similar \\
\hline $\begin{array}{l}\text { Interference of antidopaminergic } \\
\text { drugs }\end{array}$ & $\begin{array}{c}\text { Baseline motor symptoms may be } \\
\text { worsened }\end{array}$ & Baseline symptoms may be worsened & Somewhat similar \\
\hline Familial forms & Familial forms have been described & $\begin{array}{c}\text { Positive family history is common; } \\
\text { in some, suggestive of genetic } \\
\text { segregation }\end{array}$ & Somewhat similar \\
\hline Monogenic forms & $\begin{array}{l}\text { Various genes have been associated } \\
\text { with monogenic forms }\end{array}$ & No monogenic form described so far & Different \\
\hline Accumulation of alpha-synuclein & $\begin{array}{l}\text { Accumulation with Lewy body type } \\
\text { pathology }\end{array}$ & No pathologic accumulation & Different \\
\hline $\mathrm{TH}+$ cells in substantia nigra cells & Highly decreased & Normal & Different \\
\hline Iron content in substantia nigra & Likely to be increased & Likely to be decreased & Opposites \\
\hline
\end{tabular}


WED symptoms, a neuropathological study of patients with RLS/WED did not find abnormalities in components of the dopaminergic circuitry ${ }^{10}$. This same study demonstrated that histological markers of iron (iron staining and ferritin) were reduced in the $\mathrm{SN}$, suggesting that RLS/WED pathology may not be rooted in a traditional degenerative process but may rather be a functional disorder resulting from impaired iron acquisition by the neuromelanin cells ${ }^{10}$, a conclusion that is consonant with the finding of hypoechogenicity of the SN (implying iron deficit) detected in transcranial sonography studies of RLS/WED patients ${ }^{11}$.

In two ensuing studies, the same group later demonstrated that this finding had good sensitivity (82\%), specificity $(83 \%)$ and positive predictive value (94\%) for the diagnosis of RLS/WED and was not restricted to the SN, as the red nucleus, thalamus and brainstem raphe also showed signs of impaired iron homeostasis ${ }^{12,13}$. Of importance, in PD this same technique typically shows SN hyperechogenicity (suggesting increased iron deposition) ${ }^{11}$. On the other hand, a study that assessed brainstem and spinal pathways of RLS/ WED patients using MRI, blink reflex, exteroceptive suppression of the temporalis muscle, and $\mathrm{H}$ reflex did not reveal any gross anatomical and functional abnormality of these structures ${ }^{14}$. Another study using brain MRI confirmed the impression that RLS/WED is not related to changes in gross anatomy but also showed, using a special MRI measurement to assess iron concentrations, that iron was reduced in the SN and, to a lesser extent, in the putamen, confirming the perception drawn from sonographic studies ${ }^{10,12,13}$.

A direct neuropathological study confirmed markedlyreduced iron and ferritin staining in the SN of RLS/WED patients but did not find histopathologic abnormalities unique to RLS/WED or differences in tyrosine hydroxylase staining of dopaminergic neurons, compared with controls, in any midbrain structures ${ }^{15}$. Functional neuroimaging studies broadened these evidences. For instance, using high resolution functional MRI in patients with RLS/WED during actual episodes, Bucher et al. ${ }^{16}$ found bilateral activation of the cerebellum, thalamus, red nucleus and reticular formation. Another more complex functional imaging study used voxel-based morphometry, $\mathrm{T}_{2}$ relaxometry and functional MRI during episodes of RLS/WED, reaching a few important conclusions: the brains of RLS/WED patients do not show any volumetric change but present with increased iron content in the internal globus pallidus and subthalamic nucleus. Abnormal brain activation was observed in the thalamus, striatum, cerebellum, midbrain, pons, and several cortical areas. The interpretation of these results was that RLS/WED was related to basal ganglia and striatofrontolimbic dysfunction, the latter probably reflecting behavioural (urge, agitation, discomfort, etc.) features of the syndrome ${ }^{17}$.

With all the data generated by methodologically sound and solid investigations revealing subtle changes that denounce mainly brainstem- and basal ganglia-related abnormalities as offenders in the RLS/WED mystery, several other nervous system regions may be equally guilty by-standers. Among those that deserve to be discussed in more detail, in part due to their seemingly potential relationship with PD, are the A11 dopaminergic neurons, found in close proximity to the hypothalamic sleep nuclei. These cells are the only source of dopaminergic innervation to the spinal cord and their selective bilateral 6-hydroxydopamine lesion induces dopamine agonist-responsive motor and behavioural signs in animal models ${ }^{18}$. Other studies using this same animal model showed that an iron deficient diet induced a synergistic greater decrease in spinal cord dopamine receptor binding ${ }^{19}$. Interestingly, this same cell group is lesioned in MPTP models of PD but its changes in humans affected by PD seem to be negligible ${ }^{20}$.

Overall, the conclusion that can be drawn from these pathological and anatomical studies is that the current knowledge of the underlying pathophysiological abnormalities in RLS/ WED remains fairly hazy and dissociated, with only a few uniform and consistent findings that have not been adequately and rationally integrated. Moreover, on this basis, it seems very unlikely that RLS/WED represents one of the facets of a neurodegenerative syndrome, as in the case of hyposmia or REM sleep behavior disorder in the context of $\mathrm{PD}^{21}$.

\section{GENETIC DATA}

A distinct facet that could link RLS/WED and PD would be a common genetic basis. However, a detailed molecular study of known loci (MEIS1, BTBD9, and MAP2K5-LBXCOR1) correlated for RLS/WED susceptibility in 369 PD patients (10 of them presenting with coexisting RLS/WED) did not find evidence of a high prevalence of the polymorphisms analyzed compared to controls ${ }^{22}$. A more recent study, analyzing a larger population (1,133 cases) of PD patients, including another genetic marker for RLS/WED susceptibility (PTPRD) in addition to the three studied previously, also did not detect any evidence of an association of the genetic variants with PD risk ${ }^{23}$.

More evidence for lack of a connection between RLS/ WED and PD comes from a study of two families with RLS/ WED and parkin mutations. Biallelic parkin mutations are linked to early-onset, levodopa-responsive parkinsonism, similar to PD. The role of single heterozygous mutations is controversial but most evidence leads to the thought that they are not linked to a heredodegenerative process. In the report, more than 200 individuals in these families were screened for RLS/WED, which was confirmed clinically in 20, in the range of what is expected for the general population. Among them, parkin mutations were found in only half, all heterozygous, except for one homozygous individual, who also developed parkinsonism. As expected, the clinical manifestations of RLS/WED did not differ between patients with and without the single parkin mutation ${ }^{24}$. 
Other evidences of a genetic link between the two disorders remain deceptive. For instance, molecular analysis of a family presenting with multiple neurologically-affected individuals, including those with $\mathrm{PD}$, essential tremor and RLS/WED in an apparent autosomal dominant inheritance pattern, did not reveal any positive testing for mutations in known parkinsonism-linked genes ${ }^{25}$, while another study exploring the genetic association of the COMT val158met polymorphism with RLS/WED yielded negative results ${ }^{26}$.

Overall, although various monogenic forms of PD have been described, to date none has been found for RLS/WED ${ }^{27}$.

\section{CLINICAL STUDIES}

Among the diverse angles we can inspect, the interface between RLS/WED and PD clinical studies are apparently the most fragile. Our interpretation of the literature from this standpoint is that the data are not only conspicuous suppliers of elusive evidence but also the ones more vastly populated by several forms of bias. These studies, in fact, have both intrinsic (i.e., the interference of dopaminergic treatment and RLS/WED mimics) and extrinsic (non-uniform diagnostic criteria, inadequate controls, small samples, etc.) biases that limit interpretation of results, making current evidence restricted and fragile. Compared to the general population, the distinction between true RLS/WED and its potential mimics in PD is not straightforward and includes nocturnal leg cramps, akathisia, nonspecific leg pain, dyskinesia (especially biphasic and off dystonia), parkinsonian rigidity and/or tremor per se, positional discomfort related to akinesia, "inner tremor" sensation, etc. A comprehensive list of RLS/WED mimics in PD, along with their similarities and differences, is described in Table 2. The fact that some of these confounders almost invariably fluctuate depending on the effect of dopaminergic treatment makes the distinction even more daunting.

Bearing these caveats in mind, the number of studies that looked at this correlation from the point of view of clinical prevalence is relatively large and conclusions are somewhat conflicting. On the one hand, a few studies found results that were interpreted as indications of a positive correlation between PD and RLS/WED. For example, in a study of 165 PD patients and 131 age/sex-matched healthy controls, RLS/WED was detected in $12 \%$ in PD patients and $2.3 \%$ in controls $^{28}$. In the study, the effect of RLS/WED on sleep quality was negligible and only three patients in the PD group requested treatment for RLS/WED. Before the study, none of them were aware of having RLS/WED. Similar findings were described in a study from Singapore where $3 \%$ of a cohort of $400 \mathrm{PD}$ patients and $0.5 \%$ of controls received a diagnosis of RLS/WED; both figures low compared to the known prevalence expected for the general population. The authors recognize that the association of both entities is weak and in their cohort the role of RLS/WED in sleep dysfunction was not important ${ }^{29}$. Another questionnaire-based study that paralleled these findings evaluated $126 \mathrm{PD}$ patients and 128 age/sex-matched controls, identifying RLS/WED 7.9\% in PD and $0.8 \%$ in controls ${ }^{30}$. Again, only one of the affected patients had significantly severe symptoms and the majority did not detect a clinical response to the introduction of a dopaminergic agent.

The study by Ondo and Lai. ${ }^{31}$ evaluated $303 \mathrm{PD}$ patients but no controls and found RLS/WED symptoms in $20.8 \%$; however, most were thought to have secondary RLS/WED, more commonly with low serum ferritin. Interestingly, the same group also found an even more impressive rate of RLS/ WED cases (33\%) among patients with essential tremor and vice versa ( $58.9 \%$ of 56 RLS/WED patients also had tremor) ${ }^{32}$.

Other studies found similarly higher figures without a control group: the study by Guerreiro et al. ${ }^{33}$ diagnosed RLS/WED in close to $19 \%$ in a relatively small sample of PD patients and Lee et al. ${ }^{34}$ found a $16.3 \%$ prevalence of RLS/WED in a much larger cohort of PD patients. Interestingly, in this last study, patients with RLS/WED had a longer duration of $\mathrm{PD}$, more PD-related disability, and worse cognition; however, the stronger factor related to RLS/WED on multivariate logistic regression analysis was a longer duration of dopaminergic therapy. The authors concluded that their findings suggested that long-term therapy, rather than PD itself, may contribute to the development of RLS/WED. An alternative view is that more advanced disease and longer exposure to therapy may actually be related to a higher prevalence of RLS/WED mimics, such as biphasic dyskinesias, nocturnal cramps, leg discomfort in the setting of motor fluctuations, among other conditions.

Beyond the biases inherent in each of these studies, it is also important to observe that, overall, the figures of RLS/ WED in these PD cohorts are within the scope of what is found in studies of RLS/WED in the general population of the same age ${ }^{3}$. Furthermore, the prevalence in the control groups seems to be lower than expected ${ }^{28,29,30}$. This observation may in fact indicate that the instruments used in these studies may have a suboptimal sensibility among controls and low specificity among PD patients, possibly prompted by inclusion of RLS/WED mimics.

On the other hand, a good number of clinical investigations did not find results endorsing a link between PD and RLS/WED. For example, in 269 PD patients studied in the Netherlands, $11 \%$ had definite RLS/WED, similar to the prevalence in the general population. Interestingly, the severity of RLS/WED symptoms correlated positively with the signs of PD, particularly the nondopaminergic ones ${ }^{35}$. Another study in 125 PD patients found a $15.2 \%$ prevalence of "motor restlessness" correlating, in a small proportion, with wearing off of levodopa. None of the patients satisfied the formal diagnostic criteria for RLS/WED, leading the authors to conclude that the two diseases are not linked ${ }^{36}$. 
Table 2. Potential restless legs syndrome/Willis-Ekbom disorder mimics in general and in the setting of Parkinson's disease.

\begin{tabular}{|c|c|c|}
\hline RLS/WED mimic & Similarities & Differences \\
\hline Nocturnal cramps & $\begin{array}{l}\text { Nocturnal predominance } \\
\text { Improved by stretching and massaging }\end{array}$ & $\begin{array}{c}\text { Commonly awakens the patient rather than occurring } \\
\text { while laying down to sleep but still awake } \\
\text { Abrupt onset } \\
\text { Not alleviated by movement per se } \\
\text { Typically localized }\end{array}$ \\
\hline $\begin{array}{l}\text { Peripheral sensory } \\
\text { neuropathy, radiculopathy, } \\
\text { myelopathy* }\end{array}$ & $\begin{array}{l}\text { Presents with superficial sensations described } \\
\text { as shooting, burning, tingling, pain, etc. }\end{array}$ & $\begin{array}{l}\text { Not associated with the need to move } \\
\text { No improvement with movement } \\
\text { No circadian pattern }\end{array}$ \\
\hline Akathisia & $\begin{array}{c}\text { Sensation of restlessness and muscle quivering } \\
\text { Partial relief by pacing and moving around } \\
\text { Urge to move }\end{array}$ & $\begin{array}{l}\text { Generalized sense of restlessness } \\
\text { No circadian pattern but may be more noticeable at rest } \\
\text { Improvement with movement is never complete } \\
\text { Commonly due to dopamine blocking agents }\end{array}$ \\
\hline Severe anxiety & $\begin{array}{l}\text { Sensation of restlessness } \\
\text { May be associated with urge to move }\end{array}$ & $\begin{array}{c}\text { Generalized } \\
\text { Only mild or no improvement with movement } \\
\text { No circadian pattern }\end{array}$ \\
\hline Myalgia/sore leg muscles & Pain and/or discomfort & $\begin{array}{l}\text { Not limited to the lower extremities } \\
\text { Worsened, not improved, by movement } \\
\text { No urge to move }\end{array}$ \\
\hline $\begin{array}{l}\text { Arthropathy and other } \\
\text { orthopedic disorders }\end{array}$ & Localized pain and/or discomfort & $\begin{array}{l}\text { Worsened, not improved, by movement } \\
\text { No urge to move }\end{array}$ \\
\hline $\begin{array}{l}\text { Positional discomfort } \\
\text { (numbness) }\end{array}$ & $\begin{array}{l}\text { Present at rest, improved by mobility } \\
\text { Lower limb predominance }\end{array}$ & $\begin{array}{l}\text { No circadian pattern but only noticeable at rest } \\
\text { No restlessness or urge to move }\end{array}$ \\
\hline Tics & $\begin{array}{l}\text { Associated with nonspecific discomfort } \\
\text { Urge to move } \\
\text { Relieved by movement }\end{array}$ & $\begin{array}{l}\text { Relieved by specific stereotypic movement only } \\
\text { Rarely occurs in the lower extremities } \\
\text { Commonly associated with other motor or vocal tics }\end{array}$ \\
\hline Painful legs moving toes & Lower limb pain & $\begin{array}{c}\text { No circadian pattern } \\
\text { Involuntary movements, no urge to move } \\
\text { No relief with mobility } \\
\text { Commonly associated with spinal cord or peripheral } \\
\text { lesions/trauma }\end{array}$ \\
\hline
\end{tabular}

\begin{tabular}{|c|c|c|}
\hline \multirow{3}{*}{ "Internal" tremor in PD } & $\begin{array}{l}\text { Subjective unpleasant sensation with no visible } \\
\text { limb oscillations }\end{array}$ & No circadian pattern but may be more noticeable at rest \\
\hline & Improved by movement & No urge to move \\
\hline & Improved with levodopa or dopamine agonist & $\begin{array}{c}\text { Usually lateralized symptoms in both upper and lower } \\
\text { extremities }\end{array}$ \\
\hline \multirow{3}{*}{$\begin{array}{l}\text { Rigidity as part of } \\
\text { parkinsonism }\end{array}$} & Sensation of heaviness & No circadian pattern \\
\hline & Improved with levodopa or dopamine agonist & No urge to move/no improvement with movement \\
\hline & & $\begin{array}{c}\text { Usually lateralized symptoms in both upper and lower } \\
\text { extremities }\end{array}$ \\
\hline \multirow{4}{*}{$\begin{array}{l}\text { "Off" dystonia in } \\
\text { parkinsonism }\end{array}$} & Painful, uncomfortable sensations & Typically associated with abnormal posturing \\
\hline & Lower limb predominance & No urge to move/no improvement with movement \\
\hline & Improved with levodopa or dopamine agonist & $\begin{array}{c}\text { Different circadian pattern: common during longer "off" } \\
\text { periods (morning) }\end{array}$ \\
\hline & Lower limb predominance & Involuntary random movements \\
\hline
\end{tabular}

Biphasic dyskinesias in PD Occurs during "off" periods, may improve with levodopa or dopamine agonist

No urge to move/no improvement with movement

Timing may mimic augmentation phenomena

*May predispose to true RLS; PD: Parkinson's disease; RLS/WED: Restless legs syndrome/Willis-Ekbom disease.

Lower limb motor restlessness, but not true RLS/WED, was also found in two other studies of larger controlled cohorts (200 and 436 PD patients) $)^{37,38}$. These three studies emphasized the potential role of akathisia as a RLS/WED mimic.

In the study by Peralta et al. ${ }^{39}$, RLS/WED was diagnosed in $24 \%$ out of 113 PD patients; however $61 \%$ of them presented with symptoms only during periods of wearing off of levodopa. Both studies illustrate our speculation that PD-RLS/WED clinical studies are prone to bias due to low specificity of the diagnosis of RLS/WED in the setting of PD, especially when patients develop motor fluctuations. In addition, both studies added the caveat that dopaminergic treatment may have 
underestimated the prevalence of RLS/WED. Similarly, a case control investigation of the prevalence of RLS/WED in 118 PD patients in various disease stages did not demonstrate a significantly increased prevalence of RLS/WED. The authors recognized that their cohort carried the unavoidable and intuitive limitation that most, if not all, patients examined were receiving dopaminergic treatment that could have masked unrecognized RLS/WED symptoms ${ }^{40}$. To circumvent this hurdle, two years later the same group of investigators published a similar case control study of RLS/WED restricted to 109 cases of drug-naïve PD and 116 healthy matched controls ${ }^{41}$. Again, they did not observe any clinical association between the two conditions. In their discussion, the authors hypothesized on biases, most of which are already presented in this review.

Finally, our own study of sleep and nonmotor features of 775 patients with PD found a prevalence of RLS/WED of $11.4 \%$, similar to the general population of the same age. Furthermore, this study used logistic regression analysis to assess the correlation between nonmotor disorders (dementia, psychosis and REM sleep behavior disorder) and RLS/ WED with a variety of demographic and motor variables, finding that all the nonmotor syndromes were intercorrelated and were also correlated with the disease severity based on the Hoehn \& Yahr scale score. Interestingly, RLS/WED was not correlated significantly with any of the other demographic, motor and nonmotor variables. As most of the other variables have some sort of correlation with the progression of pathologic changes typical of PD, RLS/WED behaved as a neutral variable, possibly indicating an independent occurrence, mirroring its development in the general population ${ }^{42}$. Finally, the phenomenon of augmentation, described in the introduction of this review, may muddle this scenario further, as continuous treatment with dopaminergic drugs for the management of PD motor symptoms may unmask or boost mild, subclinical RLS symptoms, yet another factor potentially inducing a higher prevalence of RLS/WED in $\mathrm{PD}^{13}$.

\section{WHAT IS THE POOLED PREVALENCE OF RLS/WED AND ITS MIMICS IN PD?}

In view of these contrasting results, what is the overall prevalence of the sum of true, secondary and mimics of RLS/WED in PD? A recently-published meta-analysis ${ }^{43}$ tried to answer this question comparing 28 clinical studies. The pooled prevalence among diverse populations was $14 \%$, being higher among those who had previously received dopaminergic treatment (15\%) than among drug-naïve patients (11\%). Differences were also marginal for gender prevalence, favoring women (13\% vs. 11\%). In their discussion, the authors were careful enough to acknowledge the intrinsic limitations of these studies, including a variety of biases.

\section{NONMOTOR FEATURES OF PD IN RLS/WED}

The possible link between RLS/WED and nonmotor features of PD could endorse its inclusion in the expanding list of possible premotor traits of the neurodegenerative process. This link, however, remains far-fetched. In the realm of sleep disorders, REM sleep behavior disorder, one of the best described and recognized of these features, has been studied in patients with RLS/WED compared with a cohort of PD patients and controls. The prevalence of REM sleep behavior disorders among RLS/WED patients was significantly lower than in PD patients but not statistically different than in controls ${ }^{44}$. Similarly, olfaction was investigated in RLS/WED patients in two studies and found to be no different from controls ${ }^{45,46}$.

Interestingly, a study of autonomic function in RLS/WED found significantly higher prevalences of sialorrhea and constipation when compared with controls, the latter becoming nonsignificant after adjustment for age, sex and medications ${ }^{47}$.

\section{CONCLUSION}

The exploration of the common symptomatic response to dopaminergic agents in PD and RLS/WED was pivotal in the understanding of their pathophysiology; however, it also served to show an apparently unexpected lack of other common features, especially in terms of their anatomical/physiologic background. In line with the latter statement, our review of the literature did not find solid evidence that these disorders are comorbidities or mutual risk factors, mainly due to the existence of multiple methodological biases in the absence of a biomarker for RLS/WED that could separate it from its mimics outlined in Table 2.

\section{References}

1. Munhoz RP, Werneck LC, Teive HA. The differential diagnoses

of parkinsonism: findings from a cohort of 1528 patients

and a 10 years comparison in tertiary movement disorders

clinics. Clin Neurol Neurosurg. 2010 Jun;112(5):431-5.

https://doi.org/10.1016/j.clineuro.2010.03.003

2. Braak H, Ghebremedhin E, Rüb U, Bratzke H, Del Tredici K. Stages in the development of Parkinson's disease-related pathology. Cell Tissue Res. 2004 Oct;318(1):121-34. https://doi.org/10.1007/s00441-004-0956-9
3. Allen RP, Picchietti D, Hening WA, Trenkwalder C, Walters AS, Montplaisi J. Restless legs syndrome: diagnostic criteria, special considerations, and epidemiology. A report from the restless legs syndrome diagnosis and epidemiology workshop at the National Institutes of Health. Sleep Med. 2003 Mar;4(2):101-19. https://doi.org/10.1016/S1389-9457(03)00010-8

4. Teive HA, Munhoz RP, Barbosa ER. Professor Karl-Axel Ekbom and restless legs syndrome. Parkinsonism Relat Disord. 2009 May;15(4):254-7. https://doi.org/10.1016/j.parkreldis.2008.07.011 
5. Aggarwal S, Dodd S, Berk M. Restless leg syndrome associated with atypical antipsychotics: current status, pathophysiology, and clinical implications. Curr Drug Saf. 2015;10(2):98-105. https://doi.org/10.2174/1574886309666140527114159

6. Jagota P, Asawavichienjinda T, Bhidayasiri R. Prevalence of neuroleptic-induced restless legs syndrome in patients taking neuroleptic drugs. J Neurol Sci. 2012 Mar;314(1-2):158-60. https://doi.org/10.1016/j.jns.2011.10.032

7. Rijsman RM, Schoolderman LF, Rundervoort RS, Louter M. Restless legs syndrome in Parkinson's disease. Parkinsonism Relat Disord. 2014 Jan;20 Suppl 1:S5-9. https://doi.org/10.1016/S1353-8020(13)70004-X

8. Pittock SJ, Parrett T, Adler CH, Parisi JE, Dickson DW, Ahlskog JE. Neuropathology of primary restless leg syndrome: absence of specific tau- and alpha-synuclein pathology. Mov Disord. 2004 Jun;19(6):695-9. https://doi.org/10.1002/mds.20042

9. Ryu JH, Lee MS, Baik JS. Sonographic abnormalities in idiopathic restless legs syndrome (RLS) and RLS in Parkinson's disease. Parkinsonism Relat Disord. 2011 Mar;17(3):201-3. https://doi.org/10.1016/j.parkreldis.2010.11.014

10. Connor JR, Boyer PJ, Menzies SL, Dellinger B, Allen RP, Ondo WG et al. Neuropathological examination suggests impaired brain iron acquisition in restless legs syndrome. Neurology. 2003 Aug;61(3):3049. https://doi.org/10.1212/01.WNL.0000078887.16593.12

11. Godau J, Schweitzer KJ, Liepelt I, Gerloff C, Berg D. Substantia nigra hypoechogenicity: definition and findings in restless legs syndrome. Mov Disord. 2007 Jan;22(2):187-92. https://doi.org/10.1002/mds.21230

12. Godau J, Wevers AK, Gaenslen A, Di Santo A, Liepelt I, Gasser T et al. Sonographic abnormalities of brainstem structures in restless legs syndrome. Sleep Med. 2008 Oct;9(7):782-9. https://doi.org/10.1016/j.sleep.2007.09.001

13. Godau J, Klose U, Di Santo A, Schweitzer K, Berg D. Multiregional brain iron deficiency in restless legs syndrome. Mov Disord. 2008 Jun;23(8):1184-7. https://doi.org/10.1002/mds.22070

14. Bucher SF, Trenkwalder C, Oertel WH. Reflex studies and MRI in the restless legs syndrome. Acta Neurol Scand. 1996 Aug;94(2):145-50. https://doi.org/10.1111/j.1600-0404.1996.tb07045.x

15. Allen RP, Barker PB, Wehrl FW, Song HK, Earley CJ. MRI measurement of brain iron in patients with restless legs syndrome. Neurology. 2001 Jan;56(2):263-5. https://doi.org/10.1212/WNL.56.2.263

16. Bucher SF, Seelos KC, Oertel WH, Reiser M, Trenkwalder C. Cerebral generators involved in the pathogenesis of the restless legs syndrome. Ann Neurol. 1997 May;41(5):639-45. https://doi.org/10.1002/ana.410410513

17. Margariti PN, Astrakas LG, Tsouli SG, Hadjigeorgiou GM, Konitsiotis S, Argyropoulou MI. Investigation of unmedicated early onset restless legs syndrome by voxel-based morphometry, T2 relaxometry, and functional MR imaging during the nighttime hours. AJNR Am J Neuroradiol. 2012 Apr;33(4):667-72. https://doi.org/10.3174/ajnr.A2829

18. Qu S, Le W, Zhang X, Xie W, Zhang A, Ondo WG. Locomotion is increased in a11-lesioned mice with iron deprivation: a possible animal model for restless legs syndrome. J Neuropathol Exp Neurol. 2007 May;66(5):383-8. https://doi.org/10.1097/nen.0b013e3180517b5f

19. Zhao H, Zhu W, Pan T, Xie W, Zhang A, Ondo WG et al. Spinal cord dopamine receptor expression and function in mice with 6-OHDA lesion of the A11 nucleus and dietary iron deprivation. J Neurosci Res. 2007 Apr;85(5):1065-76. https://doi.org/10.1002/jnr.21207

20. Gibb WR. Idiopathic Parkinson's disease and the Lewy body disorders. Neuropathol Appl Neurobiol. 1986 May-Jun;12(3):223-34. https://doi.org/10.1111/j.1365-2990.1986.tb00136.x

21. Munhoz RP, Moro A, Silveira-Moriyama L, Teive HA. Non-motor signs in Parkinson's disease: a review. Arq Neuropsiquiatr. 2015 May;73(5):454-62. https://doi.org/10.1590/0004-282X20150029
22. Vilariño-Güell C, Soto Al, Young JE, Lin SC, Uitti RJ, Wszolek ZK et al. Susceptibility genes for restless legs syndrome are not associated with Parkinson disease. Neurology. 2008 Jul;71(3):222-3. https://doi.org/10.1212/01.wnl.0000317101.67684.e3

23. Gan-Or Z, Alcalay RN, Bar-Shira A, Leblond CS, Postuma RB, BenShachar $S$ et al. Genetic markers of Restless Legs Syndrome in Parkinson disease. Parkinsonism Relat Disord. 2015 Jun;21(6):5825. https://doi.org/10.1016/j.parkreldis.2015.03.010

24. Adel S, Djarmati A, Kabakci K, Pichler I, Eskelson C, Lohnau Tet al. Co-occurrence of restless legs syndrome and Parkin mutations in two families. Mov Disord. 2006 Feb;21(2):258-63. https://doi.org/10.1002/mds.20690

25. Puschmann A, Pfeiffer RF, Stoessl AJ, Kuriakose R, Lash JL, Searcy $\mathrm{JA}$ et al. A family with Parkinsonism, essential tremor, restless legs syndrome, and depression. Neurology. 2011 May;76(19):1623-30. https://doi.org/10.1212/WNL.0b013e318219fb42

26. Mylius V, Möller JC, Strauch K, Oertel WH, Stiasny-Kolster K. No significance of the COMT val158met polymorphism in restless legs syndrome. Neurosci Lett. 2010 Apr;473(2):151-4. https://doi.org/10.1016/j.neulet.2010.02.042

27. Jiménez-Jiménez FJ, Alonso-Navarro H, García-Martín E, Agúndez JA. Genetics of restless legs syndrome: an update. Sleep Med Rev. 2018 Jun;39:108-21. https://doi.org/10.1016/j.smrv.2017.08.002

28. Nomura T, Inoue Y, Miyake M, Yasui K, Nakashima K. Prevalence and clinical characteristics of restless legs syndrome in Japanese patients with Parkinson's disease. Mov Disord. 2006 Mar;21(3):3804. https://doi.org/10.1002/mds.20734

29. Loo HV, Tan EK. Case-control study of restless legs syndrome and quality of sleep in Parkinson's disease. J Neurol Sci. 2008 Mar;266(12):145-9. https://doi.org/10.1016/j.jns.2007.09.033

30. Krishnan PR, Bhatia M, Behari M. Restless legs syndrome in Parkinson's disease: a case-controlled study. Mov Disord. 2003 Feb;18(2):181-5. https://doi.org/10.1002/mds.10307

31. Ondo WG, Vuong KD, Jankovic J. Exploring the relationship between Parkinson disease and restless legs syndrome. Arch Neurol. 2002 Mar;59(3):421-4. https://doi.org/10.1001/archneur.59.3.421

32. Ondo WG, Lai D. Association between restless legs syndrome and essential tremor. Mov Disord. 2006 Apr;21(4):515-8. https://doi.org/10.1002/mds.20746

33. Guerreiro TM, Nishikawa DR, Ferreira LC, Melo HA, Prado RC. Restless legs syndrome in Parkinson's disease: clinical characteristics and biochemical correlations. Arq Neuropsiquiatr. 2010 Dec;68(6):86972. https://doi.org/10.1590/S0004-282X2010000600007

34. Lee JE, Shin HW, Kim KS, Sohn YH. Factors contributing to the development of restless legs syndrome in patients with Parkinson disease. Mov Disord. 2009 Mar;24(4):579-82. https://doi.org/10.1002/mds.22410

35. Verbaan D, Rooden SM, Hilten JJ, Rijsman RM. Prevalence and clinical profile of restless legs syndrome in Parkinson's disease. Mov Disord. 2010 Oct;25(13):2142-7. https://doi.org/10.1002/mds.23241

36. Tan EK, Lum SY, Wong MC. Restless legs syndrome in Parkinson's disease. J Neurol Sci. 2002 Apr;196(1-2):33-6. https://doi.org/10.1016/S0022-510X(02)00020-5

37. Suzuki K, Okuma Y, Uchiyama T, Miyamoto M, Sakakibara R, Shimo $Y$ et al. Characterizing restless legs syndrome and leg motor restlessness in patients with Parkinson's disease: A multicenter case-controlled study. Parkinsonism Relat Disord. 2017 Nov;44:1822. https://doi.org/10.1016/j.parkreldis.2017.08.007

38. Gjerstad MD, Tysnes OB, Larsen JP. Increased risk of leg motor restlessness but not RLS in early Parkinson disease. Neurology. 2011 Nov;77(22):1941-6. https://doi.org/10.1212/WNL.0b013e31823a0cc8

39. Peralta CM, Frauscher B, Seppi K, Wolf E, Wenning GK, Högl B et al. Restless legs syndrome in Parkinson's disease. Mov Disord. 2009 Oct;24(14):2076-80. https://doi.org/10.1002/mds.22694 
40. Calzetti S, Negrotti A, Bonavina G, Angelini M, Marchesi E. Absence of co-morbidity of Parkinson disease and restless legs syndrome: a casecontrol study in patients attending a movement disorders clinic. Neurol Sci. 2009 Apr;30(2):119-22. https://doi.org/10.1007/s10072-009-0037-7

41. Angelini M, Negrotti A, Marchesi E, Bonavina G, Calzetti S. A study of the prevalence of restless legs syndrome in previously untreated Parkinson's disease patients: absence of co-morbid association.J Neurol Sci. 2011 Nov;310(1-2):286-8. https://doi.org/10.1016/j.jns.2011.08.012

42. Munhoz RP, Teive HA, Eleftherohorinou H, Coin LJ, Lees AJ, Silveira-Moriyama L. Demographic and motor features associated with the occurrence of neuropsychiatric and sleep complications of Parkinson's disease. J Neurol Neurosurg Psychiatry. 2013 Aug;84(8):883-7. https://doi.org/10.1136/jnnp-2012-304440

43. Yang X, Liu B, Shen H, Li S, Zhao Q, An R et al. Prevalence of restless legs syndrome in Parkinson's disease: a systematic review and metaanalysis of observational studies. Sleep Med. 2018 Mar;43:40-6. https://doi.org/10.1016/j.sleep.2017.11.1146
44. Adler CH, Hentz JG, Shill HA, Sabbagh MN, Driver-Dunckley E, Evidente VG et al. Probable RBD is increased in Parkinson's disease but not in essential tremor or restless legs syndrome. Parkinsonism Relat Disord. 2011 Jul;17(6):456-8. https://doi.org/10.1016/j.parkreldis.2011.03.007

45. McKinnon J, Evidente V, Driver-Dunckley E, Premkumar A, Hentz J, Shill H et al. Olfaction in the elderly: a cross-sectiona analysis comparing Parkinson's disease with controls and other disorders. Int J Neurosci. 2010 Jan;120(1):36-9. https://doi.org/10.3109/00207450903428954

46. Adler $\mathrm{CH}$, Gwinn KA, Newman S. Olfactory function in restless legs syndrome. Mov Disord. 1998 May;13(3):563-5. https://doi.org/10.1002/mds.870130332

47. Shneyder N, Adler CH, Hentz JG, Shill H, Caviness JN, Sabbagh MN et al. Autonomic complaints in patients with restless legs syndrome. Sleep Med. 2013 Dec;14(12):1413-6. https://doi.org/10.1016/j.sleep.2013.08.781 